\title{
Provision of Culturally Sensitive Maternity Care
}

Shahnaz Shahid* and Ayesha Anwar

Master of Science in Nursing, Aga Khan University, Pakistan

"Corresponding author: Shahnaz Shahid, Master of Science in Nursing, Aga Khan University, Pakistan, Tel: 021349335470; E-mail: shahnaz.shahid@aku.edu Rec date: Oct 07, 2015, Acc date: Nov 28, 2015, Pub date: Dec 06, 2015

Copyright: (C) 2015 Shahid S, et al. This is an open-access article distributed under the terms of the Creative Commons Attribution License, which permits unrestricted use, distribution, and reproduction in any medium, provided the original author and source are credited.

\section{Short Communication}

Care is seen as the core component of midwifery and nursing. Health care providers, consider care in terms of culturally sensitive, high quality, and evidence-based. Midwifery care aims to maintain normality throughout the perinatal period; therefore, the midwives ensure to regularly assess and evaluate their client's health. Although, the childbirth experience vary from woman to woman, but to have a positive birthing experience, the care provided by a midwife really matters to preserve the essence of childbirth being a natural physiological process.

In the 1960's Leininger's introduced "Culturally Congruent Care", which intends to provide care harmonized with an individual's cultural values, beliefs, and practices (Leininger, 1991). Provision of culturally sensitive care paves the path for individualized holistic care. It is important for the midwives to understand the important concepts of cultural diversity and homogeneity. Though, women form diverse cultures approach midwives for care, but it is crucial to keep in mind some common cultural uniformities that may have an impact on women's care.
The concept of cultural safety obligates midwives to identify and respect individual preferences and differences while providing maternity care. Women get opportunity to make decisions for self-care and simultaneously engage in it. When cultural safety is addressed, power relationships are developed between the care provider and consumer. Hence, women develop a sense of security by the midwives continuous support, and provision of choice and control. This ultimately results in an increased level of satisfaction at both the ends.

In conclusion, it is essential to introduce the concept of culturally sensitive maternity care in midwifery education and practice. The more it is learnt and applied, the better midwifery care outcomes can be achieved by conserving normalcy in childbirth.

\section{References:}

1. Leininger, M. (1991). The theory of culture care diversity and universality. In M. Leininger (Ed.), Culture care diversity and universality: A theory of nursing (pp. 5-63). New York: National League for Nursing Press. Pub. No. $15-2402$. 